\title{
Luz, câmera, ação: o uso de filmes como estratégia para o ensino de Ciências e Biologia
}

\section{Lights, câmera, action: the use of movies as an strategy for Science and Biology Teaching}

\author{
${ }^{1}$ Elaine Cristina Pereira Costa | elaynneh@yahoo.com.br \\ ${ }^{2}$ Marcelo Diniz Monteiro de Barros | marcelodiniz@pucminas.br
}

\section{RESUMO}

O presente artigo é resultado de duas edições de um curso de férias, realizado em uma Instituição de Pesquisa, cujo objetivo é discutir as possibilidades do uso do cinema para o ensino de Ciências, no Ensino Fundamental e Biologia, no Ensino Médio. A metodologia desenvolvida ao longo das aulas baseou-se na discussão de artigos científicos acerca do uso do cinema no ensino, as possibilidades e as limitações dessas atividades, relatos de experiências em sala de aula, além da exibição dos filmes. Ao longo das aulas os professores destacavam os principais conceitos que poderiam ser abordados em sala de aula, e solicitavam que os próprios graduandos anotassem, em um diário de bordo, as cenas potenciais para discussão. Foram apresentadas, ainda, possíveis conexões dos filmes que foram trabalhados ao ofício do professor. Os autores esperam ter contribuído para uma maior utilização de filmes, documentários e animações nos contextos formais de educação em Ciências e em Biologia.

Palavras chaves: Ensino de Ciências, Ensino de Biologia, Cinema como estratégia pedagógica.

\section{ABSTRACT}

This article is the result of two editions of a vacation course, held in a Research Institution, whose goal was to discuss the possibilities of using theater to teach Science in Elementary Education and Biology in high school. The methodology developed during the classes was based on the discussion of scientific papers on the use of film to teach, the possibilities and limitations of these activities, reports of experiences in the classroom, in addition to exhibition the movies. Throughout the lessons teachers highlighted the key concepts that could be addressed in the classroom, and requested that the undergraduates themselves write down in a logbook along the views, scenes that showed potential for discussion. It was also presented possible connections of the films submitted to the office of teacher. The authors hope to have contributed to the increased use of films, documentaries and animations in formal Science and Biology education.

Keywords: Science Education, Teaching of Biology, Cinema as a pedagogical strategy.

1 Instituto Oswaldo Cruz - FIOCRUZ - RJ | LITEB - Laboratório de Inovações em Terapias, Ensino e Bioprodutos Pavilhão Cardoso Fontes, $2^{\circ}$ andar, sala 52 - Manguinhos - Rio de Janeiro

2 Pontifícia Universidade Católica - MG - Professor Assistente IV do Departamento de Ciências Biológicas / Instituto Oswaldo Cruz - Doutorando em Ensino em Biociências e Saúde - Laboratório de Inovações em Terapias, Ensino e Bioprodutos - LITEB - Setor de Inovações Educacionais 


\section{INTRODUÇÃO}

Despertar o interesse e a curiosidade dos alunos durante as aulas pode representar um constante desafio aos professores. Demo (2000) afirma que problemas na escola podem acontecer devido à falta de prazer provocada pela inadequação do ambiente escolar às expectativas sociais e culturais do aluno. Embora o interesse em aprender seja responsabilidade do aluno, o professor é parte fundamental no processo de estímulo desse interesse. Nesse sentido, Santos e Silva (2011) destacam que o lúdico, quando utilizado pelo professor como estratégia de ensino, deve trazer curiosidade, prender a atenção, instigar os alunos a se interessarem pelo que está sendo proposto, facilitando a compreensão do conteúdo lecionado, deixando-os entretidos, curiosos e concentrados.

Educar não se limita a repassar informações ou mostrar apenas um caminho, aquele que o professor considera como sendo o mais correto, mas é ajudar a pessoa a tomar consciência de si mesma, dos outros e da sociedade, oferecendo várias ferramentas para que o aluno possa escolher entre os vários caminhos possíveis, aquele que for compatível com seus valores, sua visão de mundo e com as circunstâncias adversas que ainda encontrará em seu futuro (ROJAS, 2002). De acordo com Zanella, Christ e Souza (2008), cada aluno apresenta diferentes formas de aprendizagem e, desta forma, o professor deve explorar diferentes recursos, a fim de desenvolver os conceitos científicos, enfatizando como eles fazem parte de nossa vida, bem como a importância dos mesmos.

Com frequência, o que se percebe na escola é que o aluno não problematiza, não questiona, se limitando a receber e acomodar o conhecimento passado, de forma desvinculada da realidade em que vive. Entretanto, reconhecemos que o conhecimento se dá nas relações sujeito-objeto-realidade com a mediação do professor (PINTO e TAVARES, 2010).

Muitas pessoas ainda desconhecem a importância do lúdico no desenvolvimento das crianças e que é por meio dele que elas adquirem experiências e desenvolvem seu conceito sobre o mundo que as cerca (OLIVEIRA e SILVA, 2007). Assim, a escola pode ser um ambiente propício para abordagens diferenciadas do método de ensino tradicional.

A imaginação e a curiosidade também constituem um diferencial no momento da aprendizagem científica. De acordo com Pietrocola (2004, p. 130), as atividades científicas tornam-se importantes e instigadoras quando são capazes de excitar nossa curiosidade. Dessa forma, através da nossa imaginação, o pensamento passa a apreender o desconhecido buscando uma explicação para os enigmas. A curiosidade serve então de fio condutor para as atividades, que não teriam o mesmo significado, caso fossem meramente burocráticas e exercidas com o propósito de cumprir obrigações. Pode-se afirmar que a curiosidade nasce do desconhecido que pode de alguma forma ser apreendido pela imaginação.

Dentre tantos recursos didáticos que podem ser utilizados pelo professor a fim de oportunizar e facilitar o processo de aprendizado dos alunos, destacamos no presente trabalho o uso do cinema em sala de aula. Estudo de Oliveira (2006) registra que mesmo sabendo que são montadas, a magia e o encantamento do fluxo de imagens fazem o espectador reagir como se fosse a própria realidade.

Alguns trabalhos de pesquisa associando o cinema ao ensino das biociências já foram realizados. Nesse viés, é pertinente destacar os estudos de Caixeta et al, 2010, que desenvolveram um guia do educador para que os professores do ensino médio pudessem trabalhar o filme "Eu Christiane F, 13 anos, drogada e prostituída..." em sala de aula; Gomes-Maluf e Souza, 2008, aproximaram a ficção científica do ensino de ciências, através do estudo do filme “Jurassic Park”. Brendim et al, 2007, analisaram a produção de vídeos educativos em prevenção e detecção precoce dos cânceres de cabeça e pescoço, visando uma formulação, nos aspectos pedagógicos e instrucionais, para alunos de cursos superiores da área de saúde. Rezende e Struchiner, 2009, pesquisaram um vídeo educativo acerca dos insetos, discutindo a adequação do material investigado para as aulas de Ciências do Ensino Fundamental. Barros, Girasole e Zanella, 2013, investigaram como e com que frequência, professores de 
Ciências e de Biologia fazem uso do cinema como estratégia de ensino e, no mesmo artigo, ainda apresentaram uma lista sugerindo 83 filmes que podem ser utilizados para ensinar Ciências e Biologia.

\section{METODOLOGIA}

O presente trabalho foi desenvolvido durante o Curso de Férias oferecido em uma Instituição de Pesquisa, em duas edições, a primeira com carga horária de 20 horas e a segunda com 40 horas. O pré requisito exigido pela instituição era que os alunos fossem graduandos, não sendo autorizada a participação a pessoas já formadas em curso superior.

A metodologia desenvolvida ao longo das aulas baseou-se na discussão de artigos científicos acerca do uso do cinema no ensino, as possibilidades de abordagens desses materiais, as limitações dessas atividades, relatos de experiências em sala de aula, além da exibição dos filmes. Na dinâmica das aulas, os professores destacavam os principais conceitos que poderiam ser abordados em sala de aula, além de solicitar que os próprios graduandos anotassem ao longo das exibições as cenas que também poderiam ser destacadas, a fim de exercitar o olhar dos alunos do curso acerca das possibilidades oferecidas em cada filme.

Caracterizando nossa amostra, o curso foi realizado em sua $1^{\text {a }}$ edição com 4 alunos, 3 do sexo feminino e 1 do sexo masculino, com carga horária de 20 horas, em julho de 2012. A edição seguinte, contou com 8 pessoas do sexo feminino, cuja carga horária foi aumentada para 40 horas e foi realizada em janeiro de 2013. Caracterizando o grupo das duas edições juntos, o total foi de 12 alunos, dos quais 6 eram oriundos da rede pública de ensino superior e 6 da rede privada, cuja faixa etária variou entre 18 e 39 anos. A formação acadêmica dos alunos era predominantemente constituída por graduandos de Biologia (9), seguidos de Pedagogia (2) e uma aluna de Biomedicina; os graduandos estavam distribuídos entre o $2^{\circ}$ e o $10^{\circ}$ períodos, o que tornou a turma bastante diversificada em relação ao nível de conhecimento e a experiência em práticas pedagógicas.

Para melhor estruturar a nossa avaliação, em relação ao impacto do curso, utilizamos como instrumento de coleta de dados um questionário no primeiro encontro e outro na última aula do curso. Os questionários, que são os principais instrumentos de coleta de dados para a prática da pesquisa descritiva (Vieira, 2009), continham perguntas abertas. Ao longo das aulas, das discussões dos filmes e dos artigos estudados, os pesquisadores registraram através de anotações os principais pontos destacados pelos alunos, bem como suas dúvidas e sugestões de uso dos materiais, que foram sistematizados utilizando o instrumento qualitativo diário de bordo (ZABALZA, 2004) e será mais detalhado na seção dos resultados do presente artigo. A opção pelo diário de bordo se justifica na medida em que o referido pode ser entendido como um importante mecanismo de investigação e de desenvolvimento profissional, se configurando como um importante instrumento de pesquisa qualitativa, tanto na formação inicial como na formação continuada de professores. Além disso, o diário de bordo permite o exercício da reflexão, o enfrentamento de dilemas e a sistematização planejada e ordenada do trabalho docente.

O primeiro questionário entregue aos graduandos visava coletar informações acerca da motivação inicial para participação no curso, das possibilidades que eles enxergavam antes das aulas sobre o uso do cinema no ensino, além das experiências como professor e com o uso do cinema enquanto alunos não só de graduação, como também ao longo da educação básica. Já o questionário final foi entregue aos graduandos na última aula, com o objetivo de conhecer a percepção geral que construíram dos temas ao longo do curso, bem como o que mais lhes chamou atenção em cada filme apresentado, realizado em forma de memória do filme. As mudanças de conceito acerca do uso do filme e dos assuntos que podem ser discutidos também foram questionadas, assim como no primeiro questionário, a fim de compararmos se houve amadurecimento das ideias iniciais e em que escala esta se deu, além de uma avaliação geral do curso, da dinâmica das aulas, da metodologia utilizada, dos filmes escolhidos e das discussões realizadas. 
Reconhecendo a diversidade de assuntos e filmes que apresentam alguma relação com temas inseridos em Ciências e Biologia, além de considerar o curto período de um curso de férias, optamos por escolher filmes e desenhos com diferentes abordagens, com o objetivo de discutir assuntos diversos, bem como de fornecer, aos graduandos, possibilidades distintas de abordagens, de acordo com o tema do filme, a saber: O milagre de Anne Sullivan (1962); O óleo de Lorenzo (1992); Eu, Christiane F, 13 anos, drogada e prostituída (1981); Amazônia em chamas (1994); Wall-E (2008); Vida de Inseto (1998); Rio (2011) e Procurando Nemo (2003).

Dada a diversidade de gêneros e conteúdo dos filmes, ao longo das aulas, temas diferentes puderam ser abordados. No filme "O milagre de Anne Sullivan" (1962), foram discutidos assuntos relevantes como educação especial, inclusão social do aluno com deficiência física e/ou mental, além do papel do professor como mediador do conhecimento de acordo com as limitações do aluno e a importância de sua sensibilidade e adaptação a esse processo tão desafiador. Já em “O óleo de Lorenzo" (1992), a genética foi o maior destaque, considerando ser um tema de difícil abordagem na sala de aula, dada sua complexidade. O uso do filme facilita não só a compreensão do mecanismo das manifestações das doenças genéticas, como também das dificuldades enfrentadas pelos pais no tratamento dos filhos, a importância do apoio familiar e da busca por respostas relacionadas à doença ao invés da aceitação passiva de certos problemas, questões de cunho científico como barreiras farmacêuticas e lucrativas no tratamento das doenças de maior interesse médico, entre outras. Para melhor subsidiar nossa discussão acerca do filme mencionado, fornecemos aos graduandos do curso o artigo intitulado "O óleo de Lorenzo: o uso do cinema para contextualizar o ensino de genética e discutir a construção do conhecimento científico” (MAESTRELLI e FERRARI, 2006), que discute a importância do tema, suas implicações na sociedade e também no enfrentamento dos problemas e da dor em famílias que possuem um portador de ALD, discutindo com os alunos questões éticas, médicas, genéticas, psicológicas, sociais e financeiras apresentadas ao longo do filme.

O filme Eu, Christiane F, 13 anos, drogada e prostituída (1981), permitiu reflexões acerca do uso de drogas, infelizmente um aspecto tão presente e grave na juventude brasileira, realçando ainda mais a importância deste tema, além da influência das amizades na adolescência e juventude. O filme também permite destaques acerca da dependência química e dos recursos degradantes e progressivos que levam seus usuários para sustentarem o vício, como a prostituição e o roubo, por exemplo. Em Amazônia em chamas (1994), foram enfatizados problemas de cunho ambiental, envolvendo política e interesses econômicos que ignoravam os anseios e direitos dos trabalhadores e suas famílias. A história de Chico Mendes é contada de forma forte e dramática neste filme, em que sua luta em defesa da conservação ambiental custa sua própria vida e a de outros companheiros.

Embora tratem de temas distintos, os quatro filmes citados anteriormente apresentam algo em comum e que os tornam ainda mais relevantes: todos são casos verídicos. Essa informação permite que o material seja ainda mais atrativo, dada a maneira como as diferentes realidades e questões são exibidas nos mesmos. São temas de extrema relevância e podem ser discutidos em turmas do Ensino Médio, já que as questões apresentadas permeiam a faixa etária desses alunos. Inclusive, para melhor complementar as aulas, os pesquisadores buscaram informações atuais sobre os casos discutidos nos filmes e puderam enriquecer ainda mais os fatos apresentados, mencionando outras informações que não constavam nos filmes.

O filme Wall-E (2008), apesar de ser apresentado como um desenho, trata de questões sérias envolvendo o desenfreado avanço da tecnologia e o quanto o desrespeito ao meio ambiente e ao planeta Terra como um todo é refletido sobre a humanidade, com graves consequências. Além dessas, questões relacionadas ao lixo, reciclagem, trabalho, relações humanas, sedentarismo e obesidade a curto, médio e longo prazo também podem ser evidenciadas com o filme.

Já os filmes de animação Vida de Inseto (1998); Rio (2011) e Procurando Nemo (2003), atraem mais o público infantil, constituindo assim opções altamente recomendadas para aulas de Ciências em turmas do Ensino Fundamental tanto do I segmento quanto do II. Apesar de contarem histórias diferentes, os filmes supracitados trazem em comum a vida animal, a beleza e riqueza da biodiversidade, relações entre os animais, sendo uma interessante oportunidade para discutir as cadeias e teias alimentares, questões ambientais e o impacto negativo 
de diversas ações humanas sobre o ecossistema, podendo ser refletidas posteriormente em problemas climáticos que, inevitavelmente, afetam o homem, a agricultura, os animais e o equilíbrio do planeta.

Os filmes de animação permitem diversão e aprendizado ao mesmo tempo, já que cada personagem é um animal, constituindo-se em uma rica oportunidade para o campo da Zoologia, pois permite múltiplas abordagens sobre os diferentes grupos, habitats, nichos ecológicos, dimorfismos sexuais, comportamentos, alimentação e hábitos de vida de peixes, mamíferos, aves, insetos, além das subdivisões e particularidades de cada grupo animal. Nessa perspectiva, se descortinam possibilidades para que os professores trabalhem abordagens morfológicas, ecológicas, etológicas, entre outras, dependendo do nível de abstração e criatividade de cada um dos docentes.

\section{RESULTADOS E DISCUSSÃO}

Como trabalho final do curso, os graduandos apresentaram um seminário em que fizeram um recorte de um filme, documentário, vídeo ou desenho, a fim de exibir o que usar do material escolhido. Os graduandos também elaboraram um guia do educador que visava indicar os assuntos que poderiam ser discutidos em sala de aula a partir do trecho escolhido por eles, além das estratégias de abordagem do tema que o professor pode utilizar.

Ao longo da realização do curso, os alunos destacaram diferentes percepções acerca do uso de filmes como estratégia de ensino, além de outros aspectos discutidos no decorrer das aulas. Para melhor sistematizar essas informações, estruturamos as questões discutidas e destacadas no decorrer de cada filme e, baseados na metodologia proposta por Zabalza (2004), elaboramos um Diário de Bordo, como instrumento de pesquisa qualitativa, descrito a seguir:

\section{Filmes verídicos:}

\section{1 - O milagre de Anne Sullivan}

Temas, contextos e situações que foram percebidos pela turma:

- Educação Especial;

- Deficiência física x deficiência mental;

- Limites para educação dos filhos, ainda que sejam deficientes;

- Dificuldades da família em lidar com filhos deficientes;

- Papel da professora: paciência, compromisso, dedicação, insistência, preocupação em estudar antes de ensinar, pulso firme para questões comportamentais, acreditar no potencial do aluno.

Relação professor-aluno no filme foi iniciada de forma turbulenta, mas foi amorosa no final, dado o reconhecimento do papel de Anne Sullivan.

Falas de personagens do filme que subsidiaram partes das discussões:

\footnotetext{
"Escrever faz mal."

"Como pode reclamar de algo que você vê?”

"Culpa de quem?”

"Como posso colocar algo na cabeça dela?"

"Esperam que uma cega ensine outra?"

"É como soletrar para uma parede."

"Ela é uma macaca muito esperta."

"Obediência sem compreensão é uma cegueira."
} 


\section{2 - O óleo de Lorenzo}

Temas, contextos e situações que foram percebidos pela turma:

- Ciência: limites, interesses, produção de fármacos, comunidade científica, financiamento para pesquisas, comunicação e competição entre os cientistas, prioridade nas investigações de doenças, etapas do método científico, importância dos congressos e simpósios para discussão de resultados encontrados por cientistas de diferentes partes do mundo.

- Família: dificuldades em lidar com doenças genéticas e degenerativas, crise no casamento em virtude das preocupações e do sofrimento, sentimento de impotência frente à doença, afastamento dos demais parentes, negação ao problema por parte da mãe no início; os pais eram insistentes, corajosos e inconformados com a doença do filho e a falta de respostas da medicina.

- Genética: doenças cromossômicas ligadas ao sexo, expressão de genes, sinais e sintomas da adrenoleucodistrofia, doenças genéticas que não se manifestam no nascimento; importância do mapeamento genético.

Falas de personagens do filme que subsidiaram partes das discussões:

“Ele não deveria sofrer por nossa ignorância.”

"Ele espera isso de nós."

"Pensei que a ciência médica estava a serviço dos sofredores."

"A ciência tem seu próprio tempo."

"Os ouvidos ouvem bem, mas o cérebro não consegue explicar."

"O processo é ininterrupto, o fim é inevitável, as crianças morrem em até dois anos após o diagnóstico."

"Herança ligada ao sexo: o tipo mais cruel de loteria genética."

"Os cientistas não têm os mesmos interesses que os pais."

"Se uma pessoa não pode ver, se mover ou ouvir, como podemos saber o que se passa na sua alma?"

\section{3 - Eu, Christiane F., 13 anos, drogada e prostituída}

Temas, contextos e situações que foram percebidos pela turma:

- Família: desestruturada, indicando a ausência do pai e atenção pela mãe de forma bastante superficial;

- Amizades: Buscando aceitação dentro da turma, Christiane começa a consumir haxixe, maconha e pílulas estimulantes;

- Drogas: Por que a droga vicia, quais são os componentes que causam essa dependência. Os mecanismos e a efetividade das drogas utilizadas para a desintoxicação;

- Paralelo entre a heroína (que não é uma droga muito consumida no Brasil devido ao seu alto custo), o Crack e a Metanfetamina. É importante informar que o Crack é uma das drogas mais consumidas no Brasil e a Metanfetamina, nos EUA;

- Prostituição e o compartilhamento de agulhas, é possível abordar doenças que podem se propagar de uma forma ou de outra (ou de ambas): hepatite, gonorréia, sífilis, AIDS, etc.

Os conceitos de neurotransmissão, sinapse e o mecanismo de ação de neurotransmissores são assuntos que podem ser abordados logo após as cenas em que Christiane começa a se drogar.

Seria interessante para um professor de História abordar o aspecto histórico da Alemanha na década de 60 e 70. A divisão entre Europa Oriental e Ocidental, as conseqüiências da construção do Muro, que se localizava próximo ao conjunto onde Christiane morava. 


\section{4 - Amazônia em chamas}

Temas, contextos e situações que foram percebidos pela turma:

- Política: Hierarquia abusiva - "ele sabia da punição quando resolveu fundar o sindicato";

- Negligência do poder federal, certamente sabia do que se passava e das injustiças cometidas naquela região, não só com o povo como também com a terra;

- Compra de votos, dificuldade em competir com quem é desleal;

- Ataques que custavam a vida de algumas pessoas, inclusive no início do filme, quando um homem é queimado em praça pública;

- Polícia: omissão de alguns casos de homicídios ao longo dos confrontos;

- Ética: Chico Mendes era "ruim de negociação”, ou seja, não era subornáve;Pagamento pelos produtos dos trabalhadores: descontos injustos, taxas abusivas, extorsão, "porque sou chefe, sou ganancioso, sou sanguessuga";

- As mortes que ocorrem ao longo do filme expressam a falta de ética, inclusive dentro da política;

- Economia: Extração da borracha não é rentável;

- Ambiente: Impacto ambiental afeta os ecossistemas;

- Desmatamento;

- Aquecimento global: ação humana é refletida em prejuízos ambientais, além das causas naturais;

- Efeito estufa;

- Perdas de ervas medicinais contra importantíssimos tratamentos médicos, envolvendo doenças graves como câncer, AIDS e outras;

- Sociedade: Capacidade de liderança de Chico Mendes, aliada ao comprometimento do povo em expor a própria vida em defesa dos direitos;

- Movimento social: povo desarmado, Chico Mendes foi torturado, apanhou, levou choques, mas não desistiu; reivindicação passiva;

- O reconhecimento e apoio da comunidade foram fundamentais para a motivação de Chico Mendes;

- Cultura: Lendas e crenças locais: Curupira reforçava o que não deveria ser feito na floresta.

Falas de personagens do filme que subsidiaram partem das discussões:

"Ele é seu amigo, não meu, ele não vale nada pra mim".

"Nós podemos escolher em que parte da cadeia queremos estar"

"Quando cortarem todas as árvores, passaremos fome juntos".

"Essa terra não é boa, não nasce nem erva daninha".

"Não há educação sem organização ou não há organização sem educação?”

\section{Filmes de animação:}

\section{1 - Wall-E}

Temas, contextos e situações que foram percebidos pela turma:

- Ambiente;

- Degradação;

- Fim da vida na Terra;

- Adaptação e evolução, a barata como única sobrevivente, altamente resistente;

- Geologia: composição do solo;

- Destino do lixo;

- Fotossíntese; 
- Atmosfera;

- Sustentabilidade;

- Decomposição, degradação de substâncias tóxicas, tempo em que a Terra levou para se recuperar dos efeitos tóxicos;

- Tecnologia;

- Produção e consumo em larga escala;

- Tudo é robotizado, inclusive as conversas entre as pessoas;

- Inovações tecnológicas: limites e importância;

- Modo de vida;

- Sedentarismo crônico;

- Obesidade desde o nascimento;

- Alimentação por fast food o tempo inteiro;

- Perda de estrutura óssea, alimentação pobre em cálcio.

Falas de personagens do filme que subsidiaram partes das discussões:

"Não precisa andar!"

“Os níveis de produtos tóxicos tornaram a terra insustentável.”

"Eu não quero sobreviver, eu quero viver.”

\section{2 - Vida de Inseto}

Temas, contextos e situações que foram percebidos pela turma:

- Biodiversidade: Artrópodes (insetos e aracnídeos) e moluscos; Aves.

- Zoologia: Insetos possuem seis patas, entretanto alguns deles apresentavam apenas quatro patas no filme como foi observado nas formigas. Os aracnídeos (aranhas e opiliões) apresentam oito patas e não possuem asas. Os caracóis possuem um corpo mole e uma concha calcárea;

- A metamorfose da lagarta até se transformar em borboleta;

- Gafanhotos fazem a muda do exoesqueleto;

- Bicho-pau = camuflagem;

- Moluscos terrestres se desidratam em contato com o sal;

- Ciclo de vida dos insetos;

- Cadeia alimentar = sementes - gafanhotos - pássaro;

- Botânica: Germinação da semente (depende de água, sol e terra);

- A dispersão das flores pode ocorrer através do vento;

- A planta tem espinhos, que servem como defesa contra herbivoria;

Aspectos históricos - exploração:

Os gafanhotos exploram o trabalho das formigas, pois estas reservam alimento para o inverno, enquanto os gafanhotos não tem este tipo de preocupação e querem que as formigas peguem alimentos para eles.

Organização social - Hierarquia:

- Sociedade das formigas;

- A sociedade possui um líder e os outros elementos possuem um determinado papel nesta sociedade. 


\section{3 - Rio}

Temas, contextos e situações que foram percebidos pela turma:

- Biodiversidade: Ararinha-azul = diferenças entre macho e fêmea; João-de-barro;

- Avestruz = ave que não voa;

- Ato de voar = Instinto natural, está no DNA;

- Tanatose = estratégia de defesa dos animais que se fingem de mortos (as ararinhas na gaiola);

- O morcego estava entre as aves, pois provavelmente foi capturado pelos contrabandistas que achavam que fosse uma ave;

- Os micos que apareceram no filme provavelmente são espécies introduzidas;

- Cadeia alimentar = sapo - serpente;

- Contrabando de espécies / organização criminosa:

- Biopirataria - Espécies são capturadas ilegalmente em seus locais de origem e levadas para outros países com fins comerciais;

- As espécies são retiradas de seu habitat natural, podendo futuramente tornar-se extintas.

- A ave era treinada para realizar apresentações;

- Problema social = a criança sem família aceitou roubar as aves em troca de dinheiro;

- Domesticação das espécies = "Domesticado demais".

- Pesquisa: Cruzamento em cativeiro dos únicos indivíduos da espécie ararinha-azul a fim de salvá-la da extinção;

- Ornitologia;

- Aviário no Rio Zoo era utilizado para recuperar as aves apreendidas;

- Identificação da espécie realizada de forma equivocada.

- Rio de Janeiro: Inserido no bioma Mata Atlântica, que apresenta uma grande diversidade de fauna e flora;

- Os pontos turísticos do Rio de Janeiro (Corcovado, Pão de Açúcar, Bonde de Santa Teresa, Sambódromo, Praia de Copacabana);

- Cultura: Carnaval e Futebol;

- Favelas cariocas.

\section{4 - Procurando Nemo}

Temas, contextos e situações que foram percebidos pela turma:

- Impacto ambiental: Esgoto indo para o mar, navio que afundou e deixou "bombas" no fundo do mar, pesca predatória;

- Percepção humana do impacto que causa ao ambiente: O dentista achou que estava ajudando o "peixinho perdido no coral, que estava tentando sobreviver".

- Diversidade biológica: Defesas de alguns animais como o peixe do aquário que inchava quando ficava estressado; o polvo que liberava uma substância escura quando estressado ou com medo; reprodução dos peixes e das tartarugas, que, embora diferentes, apresentam em comum grande número de filhotes; peixe abissal: atraente e assustador; estrela do mar e seu anel central que permite sua regeneração; a água viva só queima nos tentáculos; peixe morto boiando e de cabeça para baixo, pode se abordar os diferentes mecanismos de defesa dos diversos animais para se proteger ou enganar o predador; pérola dentro da concha;

- Equívocos: peixes não roncam, não tossem e baleia não é peixe, não inspiram e expiram, não há poeira no fundo do mar;

- Relações ecológicas: Adaptação do peixe palhaço a anêmona; tubarão é carnívoro, fortemente atraído pelo sangue, possui várias fileiras de dentes e não é acompanhado pelo pai quando nasce; a baleia, apesar de enorme, come krill; e não tem os dentes assustadores do tubarão, é chamada de orca, baleia e jubarte; a amizade do pelicano com os peixes, a relação ali seria predatória; 
- "Peixe tem que nadar, ave tem que comer" fala do pelicano - cadeia alimentar.

- Deficiência: O Nemo não tinha complexo pela nadadeira menor (no início ela é até chamada de nadadeira da sorte), mas o pai destacava que ela era uma limitação, e com o decorrer do tempo ele também a enxerga como um problema (no aquário ele diz que não pode sair do filtro por causa dela).

\section{Interfaces com a Prática Docente}

Finalmente, gostaríamos de salientar, que como um curso de férias oferecido por uma Pós Graduação em Ensino em Biociências e Saúde, tendo como público alvo graduandos das mais diversas licenciaturas, não poderíamos deixar de mencionar as interfaces com o ensino identificadas e discutidas pelos graduandos e por nós, os autores desse artigo, em cada filme, a saber:

\begin{tabular}{|c|c|}
\hline Filmes & Interfaces com o ensino e a prática docente \\
\hline $\begin{array}{l}\text { O milagre de } \\
\text { Anne Sullivan }\end{array}$ & 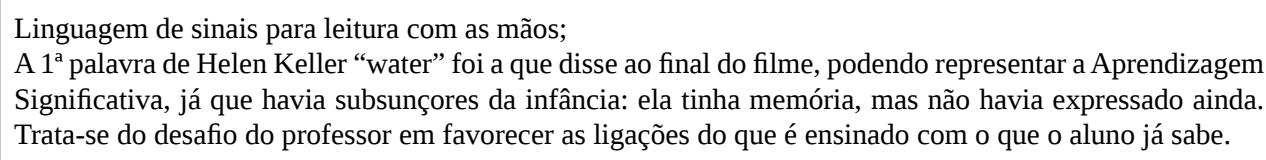 \\
\hline O óleo de Lorenzo & $\begin{array}{l}\text { Uso de modelos didáticos pelo pai de Lorenzo para explicar o mecanismo da doença, como o clips, por exemplo; } \\
\text { Uso de analogias para entender o distúrbio do excesso de ácidos graxos de cadeia longa através da pia, } \\
\text { fazendo menção à alimentação e à biossíntese; } \\
\text { Uso de gráficos para acompanhar o nível de ácidos graxos no sangue da criança a cada resultado de exame; } \\
\text { Importância da visão interdisciplinar: os pais estudaram bioquímica, fisiologia, anatomia e genética para } \\
\text { entender a doença do filho; } \\
\text { Relação mãe-escola-professor: comunicação da professora a mãe frente às estranhas mudanças de } \\
\text { comportamento de Lorenzo, buscando encontrar a causa ao invés de simplesmente punir o aluno por mau } \\
\text { comportamento. }\end{array}$ \\
\hline $\begin{array}{l}\text { Eu, Christiane F., } 13 \text { anos, } \\
\text { drogada e prostituída }\end{array}$ & $\begin{array}{l}\text { Ausência do pai na educação da filha; } \\
\text { Ausência de um espaço formal de educação na vida de Christiane; } \\
\text { Relação bastante tumultuada com a mãe, fato que pode dificultar o processo de aprendizagem. }\end{array}$ \\
\hline Amazônia em chamas & $\begin{array}{l}\text { Aspectos associados à Pedagogia da Terra (Gadotti, 2003); } \\
\text { Práticas ambientais sustentáveis; } \\
\text { Ensino dos valores; } \\
\text { Educação para a paz. }\end{array}$ \\
\hline Wall-E & $\begin{array}{l}\text { Alfabetização infantil: aprendiam as letras da nave; } \\
\text { Ensinando as crianças a plantar, regar, importância da educação. }\end{array}$ \\
\hline Vida de Inseto & $\begin{array}{l}\text { A escola muitas vezes enfatiza os erros dos alunos e desestimula o progresso dos mesmos, como foi } \\
\text { observado no filme, no momento em que a formiga Flik foi impedida de utilizar o equipamento que criou } \\
\text { para colher sementes; } \\
\text { O progresso dos estudantes, assim como os seus acertos devem ser reconhecidos pelo professor e pela } \\
\text { escola, como ocorreu com a formiga Flik. Este foi reconhecido pela sociedade por auxiliar a salvar as } \\
\text { formigas dos gafanhotos, apesar dos inúmeros erros que cometeu tentando ajudá-los. }\end{array}$ \\
\hline Rio & $\begin{array}{l}\text { Ensino de Biossegurança; } \\
\text { Ensino para a diversidade; } \\
\text { Educação Ambiental. }\end{array}$ \\
\hline Procurando Nemo & $\begin{array}{l}\text { Aula prática: faltou planejamento para o local adequado e seguro para os alunos; } \\
\text { Professor raia foi cuidadoso com os alunos, mas foi omisso em relação ao Nemo; } \\
\text { O professor é alegre, bem humorado, disposto e comprometido com o aprendizado; } \\
\text { O professor é um cientista; } \\
\text { Um peixe vermelho indica a parada do trânsito; } \\
\text { A escola é representada por brincadeiras e os alunos também zombam uns dos outros; } \\
\text { Competição e desafios impostos entre os alunos são exibidos no momento em que o Nemo arrisca encostar } \\
\text { no navio, desobedecendo o pai que o limitava diante dos colegas; } \\
\text { Uma bela exceção: somente os pais cuidam dos filhos e as mães não são exibidas no filme, exceto a mãe } \\
\text { do Nemo que morre logo no início; } \\
\text { Tema da aula: ecossistema; } \\
\text { A repetição ajuda a Dory a lembrar do endereço, a aprendizagem mecânica pode ter se tornado significativa. }\end{array}$ \\
\hline
\end{tabular}


Concordamos com Moura e colaboradores (2007) quando afirmam que o ambiente escolar, como espaço de convivência e intensas interações sociais, apresenta-se como um terreno fértil para implementação de propostas, estratégias e ações que envolvem diferentes metodologias para ampliação do conhecimento. Além disso, Oliveira et al (2008) defendem que as estratégias de ensino voltadas para ampliação da qualidade de vida, a divulgação do conhecimento científico e a articulação entre o conhecimento científico e o saber popular são essenciais na implementação de ações em educação e saúde, além de temas diversos.

De acordo com os Parâmetros Curriculares Nacionais em Ciências Naturais (BRASIL, 1998), os temas transversais destacam a necessidade de dar sentido prático às teorias e aos conceitos científicos trabalhados na escola e de favorecer a análise de problemas atuais, como Meio Ambiente e Saúde.

Assim, podemos perceber que a escola desempenha papel de grande importância no que diz respeito ao conhecimento do próprio corpo e saúde, não só na esfera física como também na psicológica, uma vez que contribui para formação do indivíduo como cidadão integrante da sociedade e participante das diretrizes por ela definidas. Contudo, segundo Ricardo (2003), a implementação dos PCN em sala de aula enfrenta dificuldades e desafios, que vão desde a formação inicial e continuada até a pouca disponibilidade de material didático-pedagógico, o que pode ser constatado também nos depoimentos dos professores no trabalho realizado por Mohr (2002). Os resultados desse estudo apontam as dificuldades encontradas pelos docentes na implementação de práticas didáticas diferenciadas que possam estimular o aprendizado e interesse dos alunos, e que sejam inovadoras em relação às aulas tradicionais, não se restringindo apenas ao uso do livro didático e do quadro, por exemplo. Contudo, não pretendemos negar a contribuição desses últimos para o aprendizado, mas salientamos apenas que a rotina desses recursos didáticos pode tornar as aulas cansativas e monótonas, ao invés de mais dinâmicas e atrativas.

\section{CONSIDERAÇÕES FINAIS}

Os autores esperam que com o desenvolvimento desse trabalho possam ter contribuído, mesmo que de forma bastante singela, para a diminuição do ensino memorístico, que privilegia o comportamentalismo. Esperam ainda uma maior utilização de filmes, documentários e animações nos contextos formais de educação, notadamente para as disciplinas de Ciências Naturais, no Ensino Fundamental, e Biologia, para o Ensino Médio.

Destacamos ainda, a riqueza encontrada em cada filme, visto que diversas áreas do conhecimento podem ser contempladas e discutidas ao longo das cenas, o que nos parece ser uma oportunidade para discutir o ensino de forma interdisciplinar, além de despertar a utilização dos recursos audiovisuais também por parte dos professores das demais disciplinas, otimizando a utilização do tempo em sala de aula de forma criativa. Cabe ressaltar que a prática de assistir filmes na escola de maneira direcionada e mediada pelo professor, destacando os aspectos relevantes e didáticos dos mesmos com os alunos, pode desenvolver nos alunos uma visão mais ampla sobre os filmes de forma geral, e fazê-los perceber as diversas mensagens que um mesmo filme pode transmitir ao telespectador, a fim de contribuir para a formação de senso crítico nos estudantes, tornando-os aptos a discutir temas polêmicos como cidadãos conscientes de seus deveres e direitos.

Desta forma, acreditamos na possibilidade de vivenciar uma escola que seja alegre, lúdica, e que promova, sempre que possível, o interesse pelo conhecimento. 


\section{REFERÊNCIAS BIBLIOGRÁFICAS}

Amazônia em chamas. Direção: John Frankenheimer. Intérpretes: Raul Julia, Sônia Braga, Edward James Olmos, Luiz Gúsman e outros. EUA: Warner Home Video, 1994. (123 min.), DVD.

BARROS, M. D. M.; GIRASOLE, M.; ZANELLA, P. G. O uso do cinema como estratégia pedagógica para o ensino de Ciências e de Biologia: o que pensam alguns professores da região metropolitana de Belo Horizonte. Revista Práxis, ano V, nº 10, p.97-116, 2013. BRASIL. Secretaria de Educação Fundamental. Parâmetros Curriculares Nacionais: Ciências Naturais / Secretaria de Educação Fundamental. - Brasília: MEC / SEF, 1998. 138p.

BRENDIM, M.P.; REZENDE, L.; SILVA, A. Entre a informação e a motivação: uma análise de vídeos educativos para prevenção e detecção precoce do câncer de cabeça e pescoço. In: VI Encontro Nacional de Pesquisa em Ensino de Ciências, 2007, Florianópolis. Atas do VI ENPEC, 2007.

CAIXETA, A.F.C.; MARTINS, L.M.A. ; BARROS, M.D.M. O cinema na sala de aula: a construção de um guia do educador para o filme Eu Christiane F., treze anos, drogada e prostituída. In: V Encontro Regional de Ensino de Biologia, 2010, Vitória. Resumos do V Encontro Regional, Vitória, 2010.

DEMO, P. Educação e conhecimento. Relação necessária, insuficiente e controversa. 3ed. Petrópolis, Rio de Janeiro: Vozes, 2000.

Eu, Christiane F, 13 anos, drogada e prostituída. Direção: Uli Edel. Intérpretes: Natja Brunckhorst, Thomas Haustein e outros. Alemanha: Solaris Film, 1981. (138 min.), VHS.

GADOTTI, M. Pedagogia da terra. 4. ed. São Paulo: Petrópolis, 217p., 2003.

GOMES-MALUF, M.C.; SOUZA, A.R. A fição científica e o ensino de ciências: o imaginário como formador do real e do racional. Ciência e Educação (UNESP. Impresso), v. 14, p. 271-282, 2008.

MAESTRELLI, S.R.P.; FERRARI, N. O óleo de Lorenzo: o uso do cinema para contextualizar o ensino de Genética e discutir a construção do conhecimento científico. Genética na Escola, v. 2, p. 35-39, 2006.

MOHR, Adriana. A natureza da educação em saúde no Ensino Fundamental e os professores de Ciências. Santa Catarina, 2002. Tese [Doutorado em Educação - Ensino de Ciências Naturais] - Universidade Federal de Santa Catarina.

MOURA, João Batista Vianey Silveira et al. Perspectiva da epistemologia histórica e a escola promotora de saúde. História, Ciências, Saúde - Manguinhos, Rio de Janeiro - v. 14, n.2, p. 489-501, abr.-jun, 2007.

OLIVEIRA, B.J. Cinema e imaginário científico. História, Ciências, Saúde - Manguinhos, v. 13 (suplemento), p. 133-50, outubro 2006.

OLIVEIRA, S.R.N.; SILVA, R. O lúdico e suas múltiplas derivações na realidade da educação infantil. Revista de Divulgação Técnico-Científica do ICPG. Vol. 3, n. 10, jan.-jun., 2007.

OLIVEIRA, Tatiana Figueiredo et al. Educação e controle da esquistossomose em Sumidouro (RJ, Brasil): avaliação de um jogo no contexto escolar. Revista Brasileira de Pesquisa em Educação em Ciências. Vol. 8, n. 3, 2008.

O Milagre de Anne Sullivan. Direção: Arthur Penn. Intérpretes: Anne Bancroft, Patty Duke, Victor Jory, Inga Swenson e outros. Roteiro: William Gibson. EUA: Classicline, 1962. (106 min.), DVD.

O Óleo de Lorenzo. Direção: George Miller. Intérpretes: Susan Sarandon, Nick Nolte, e outros. EUA: Universal Home Video, 1992. (129 min.), DVD. 
PIETROCOLA, M. Curiosidade e imaginação - os caminhos do conhecimento nas ciências, nas artes e no ensino. In: CARVALHO, Anna Maria Pessoa de (org.). Ensino de Ciências: unindo a pesquisa e a prática. São Paulo: Pioneira Thomson Learning, 2004. Vários autores.

PINTO, C.L.; TAVARES, M.H. O lúdico na aprendizagem: apreender e aprender. Revista Católica. V. 2, n. 3, p. 226-235, Uberlândia, 2010.

Procurando Nemo. Direção: Andrew Stanton e Lee Unkrich. Intérpretes: Albert Brooks, Ellen DeGeneres, Alexander Gould e outros. Austrália / EUA: Walt Disney Pictures, 2003. (100 min.), DVD.

REZENDE, L. A.2009REZENDE, L.A.; STRUCHINER, M. Uma proposta pedagógica para produção e utilização de materiais audiovisuais no Ensino de Ciências: análise de um vídeo sobre entomologia. Alexandria - Revista de Educação em Ciência e Tecnologia, v. 2, p. 45-66, 2009.

RICARDO, Elio Carlos. Implementação dos PCN em Sala de Aula: dificuldades e possibilidades. Física na Escola, v. 4, n. 1, 2003. p. 8-11.

Rio. Direção: Carlos Saldanha. Intérpretes: Anne Hathaway, Jesse Eisenberg, Leslie Mann, William e outros. Canadá / EUA: Fox filmes, 2011. (96 min.), DVD.

ROJAS, J. O lúdico na construção interdisciplinar da aprendizagem: uma pedagogia do afeto e da criatividade na escola. Rio de Janeiro: ANPED, 2002. Disponível em: <http://www.anped.org.br/25/excedentes25/ jucimararojast07.rtf >. Acesso em: 10/10/2012.

SANTOS, C.R.M.; SILVA, P.R.Q. A utilização do lúdico para a aprendizagem do conteúdo de genética. Univ. Hum., Brasília, v. 8, n. 2, p. 119-144, jul./dez. 2011.

Vida de Inseto. Direção: John Lasseter. Intérpretes: Dave Foley, Kevin Spacey, Richard Kind e outros. EUA: Buena Vista, 1998. (107 min.), DVD.

VIEIRA, S. Como elaborar questionários. São Paulo: Atlas, 2009.

Wall-E. Direção: Andrew Stanton. Intérpretes: Ben Burtt, Elissa Knight e outros. EUA: Buena Vista International, 2008. (103 min.), DVD.

ZABALZA, M.A. Diários de aula: um instrumento de pesquisa e desenvolvimento profissional. Porto Alegre: Artmed, 2004. 160 p. (Biblioteca Artmed).

ZANELLA, E.Z.; CHRIST, K.B.; SOUZA, L.C. Atividade com filme no ensino de Ciências - filme “Dinossauro”. Instituto de Ciências Biológicas - Universidade de Brasília, 2008. 